\title{
(Re)Conhecendo a Escuta como Recurso Terapêutico no Cuidado à Saúde da Mulher
}

\author{
Recognizing Listening as a Therapeutic Resource in the Care for Women's Health \\ Reconociendo la Escucha como Recurso Terapéutico en la Atención a la Salud \\ de las Mujeres
}

\author{
Suzy Anne Lopes de Souza \\ Lia Márcia Cruz da Silveira ${ }^{1}$ \\ Universidade Federal do Rio de Janeiro
}

\begin{abstract}
Resumo
A Atenção Básica é a principal porta de entrada do sistema de saúde em que, normalmente, ocorre o acolhimento das demandas do público em geral e, em especial, do feminino. Evidencia-se, portanto, a necessidade de profissionais qualificados por meio da escuta. Este estudo objetiva analisar o (re) conhecimento da escuta como recurso terapêutico pelos profissionais de saúde que atuam na assistência à saúde da mulher na Atenção Básica. Os resultados evidenciam discrepâncias entre o que é preconizado pelas políticas e a realidade nos serviços de saúde, assim como o discurso dos profissionais acerca da escuta, demonstrando conhecimento sobre o conceito, mas não sobre a prática. Em relação ao gênero, existe a compreensão das questões relacionadas à mulher, mas não das repercussões na saúde.

Palavras-chave: acolhimento, formação profissional em saúde, assistência integral à saúde da mulher
\end{abstract}

\begin{abstract}
The Primary Care is the main entrance to the health system and is the system that receives the demands of the general public, and especially women. Therefore, the need for qualified professionals is evidenced through listening. This study aims to analyze the acknowledgement of hearing as a therapeutic resource by health professionals who work in the health care of women in the Primary Care system. The results show discrepancies between what has been advocated by policies and the reality in health services, as well as in the professionals' discourse about listening, which demonstrates knowledge about the concept but not about the practice. Regarding the gender, there is an understanding of issues related to women, but not of the repercussions on health.

Keywords: hosting, human resource training in health, comprehensive health care
\end{abstract}

\section{Resumen}

La Atención Básica es la principal puerta de entrada del sistema de salud y es donde normalmente ocurre la acogida de las demandas del público en general y en especial el femenino. Se evidencia, por lo tanto, la necesidad de profesionales calificados, por medio de la escucha. Este estudio objetiva analizar el (re) conocimiento de la escucha como recurso terapéutico por los profesionales de salud que actúan en la asistencia a la salud de la mujer en la Atención Básica. Los resultados evidencian discrepancias entre lo que es preconizado por las políticas y la realidad en los servicios de salud, así como el discurso de los profesionales acerca de la escucha, demostrando conocimiento sobre el concepto, pero no sobre la práctica. En cuanto al género, existe la comprensión de las cuestiones relacionadas con la mujer, pero no de las repercusiones en la salud.

Palabras-clave: acogimiento, capacitación de recursos humanos en salud, atención integral de salud

\section{Introdução}

A Residência Multiprofissional em Saúde articula ensino-assistência e tem o objetivo de estimular e propiciar mudanças no modelo de formação dos profissionais de saúde mediante a formação em serviço, auxiliando na capacitação desses profissionais, sobretudo no desenvolvimento de práticas assistenciais no contexto do Sistema Único de Saúde (SUS). Dentre essas práticas, as discussões sobre gênero e suas implicações na saúde são frequen-

\footnotetext{
${ }^{1}$ Endereço para contato: Rua Bulhões de Carvalho, 329/702- Copacabana, Rio de Janeiro, RJ CEP 22081-000, Tel: 21- 988778786
} 
tes no cotidiano da Residência em Saúde da Mulher, que busca abordar diversos aspectos que constituem e perpassam a sua vida. Estar imersa nesse campo como residente me fez refletir sobre a importância de considerar a escuta e, nela, as questões de gênero ao prestar assistência à mulher que busca cuidado em saúde.

Ao considerar que as mulheres são as principais usuárias do SUS e não somente o utilizam para o seu próprio atendimento, mas, sobretudo, para acompanhar crianças e outros familiares, pessoas idosas, com deficiência, vizinhos e/ou amigos (Brasil, 2004), mostra-se a importância de atentarmos para as demandas próprias dessa população, refletindo sobre a influência das questões de gênero na saúde e no adoecimento. Como a Atenção Básica se configura como o nível de atenção à saúde em que, na maioria das vezes, ocorre o acoIhimento das demandas do público feminino, evidencia-se, assim, a necessidade de profissionais qualificados que atentem para as singularidades dessa população, considerando as diversas particularidades do "ser mulher" que repercutem diretamente em sua saúde.

Nesse modelo assistencial proposto, a Atenção Básica configura-se como a principal porta de entrada ao sistema de saúde, funcionando como coordenadora do cuidado do usuário nas demais Redes de Atenção, visando garantir à população acesso a uma assistência à saúde de qualidade (Brasil, 2012). A Rede de Atenção à Saúde (RAS) é um arranjo organizativo de ações e serviços de saúde que visa melhorar o desempenho do Sistema de Saúde por meio de relações horizontais entre os pontos de atenção, tendo como eixo de comunicação a Atenção Básica, em razão do foco nas necessidades de saúde da população e responsabilização na atenção contínua e integral (Brasil, 2010). Essa mudança da lógica tradicional médico-centrada para uma prática assistencial em equipe voltada às necessidades da população tem como base de atuação o vínculo com a comunidade e a responsabilização dos profissionais pelas ações de saúde coletivas e individuais (Matumoto et al., 2005).

Segundo Campos (1997), a facilidade de acesso aos profissionais de saúde e o cuidado longitudinal que a Atenção Básica propõe tornam esse nível de cuidado um contexto estratégico para estreitar o vínculo com o paciente e buscar uma ação terapêutica resolutiva. Para o autor (Campos, 1997), não há construção de vínculo sem que o usuário seja reconhecido na condição de sujeito, que fala, julga e deseja. Por sua vez, Gonze (2009) destaca que o acoIhimento, a produção de vínculos e a escuta, negligenciados diante do aparato tecnológico das máquinas de última geração, são resgatados por meio do princípio da integralidade que sustenta que o usuário é um sujeito complexo e suas necessidades devem ser acolhidas sob um olhar integral. Já para Merhy (2002b), a integralidade do cuidado à saúde requer escuta, acolhimento e ações resolutivas que culminem com a humanização das práticas.

Na literatura, algumas expressões são utilizadas para nomear a escuta como processo terapêutico, como escuta ativa, escuta integral ou atenta, escuta qualificada e escuta terapêutica. Neste trabalho, adotaremos a expressão escuta terapêutica por ter como fundamento a valorização do paciente como sujeito, possibilitando que este se reinvente ao se reconhecer como sujeito e agente ativo no processo de cuidado. Dessa forma, o usuário se percebe como protagonista de seu cuidado, exercendo, assim, um papel tão importante quanto o do profissional de saúde nas suas interações (Souza, Pereira, \& Kantorski, 2003).

Nesta perspectiva, compreendemos que o cuidado começa na escuta, ou seja, é no espaço oferecido ao usuário para que possa falar e expor suas necessidades que é possível produzir atos, ações, procedimentos e cuidados com os quais pode se chegar à cura/cuidado que 
repercute em modo qualificado de se levar a vida (Merhy, 2002a). Portanto, a escuta tem uma função terapêutica atrelada à inclinação do profissional em proporcionar acolhimento, cuidado e atenção (Rinaldi, 2000) e depende da valoração da "dimensão dialógica do encontro, isto é, a abertura para um autêntico interesse em ouvir o outro" (Ayres, 2004, p. 23).

No que diz respeito à saúde da mulher, percebe-se a importância de o cuidado em saúde ser pautado no acolhimento com escuta sensível às necessidades, considerando a influência das relações de gênero no processo de saúde e adoecimento (Coelho, Silva, Oliveira, \& Almeida, 2009). Essa escuta proporciona um cuidado em saúde que reconhece as necessidades da mulher para além das especificidades reprodutivas, com base no pressuposto da integralidade, considerando as especificidades de saúde da população feminina e as diversas implicações de "ser mulher" na atualidade (Brasil, 2004).

Segundo Souto (2008), a integralidade e a perspectiva de gênero precisam repercutir nas práticas de saúde, "desde o acolhimento até a recuperação de homens e mulheres, condições sine qua non para a humanização e qualidade da atenção à saúde que implicam o estabelecimento de relações entre sujeitos" (p. 176). De acordo com esse entendimento, Scott (1995) conceitua gênero como uma construção social sobreposta a um corpo sexuado. É construído e alimentado com base em símbolos, normas e instituições que definem modelos de masculinidade e feminilidade e padrões de comportamento aceitáveis ou não para homens e mulheres, levando em conta a subjetividade de cada sujeito, sendo única sua forma de reagir ao que lhe é oferecido em sociedade.

Para compreendermos a singularidade do atendimento à mulher, é importante refletirmos sobre as modificações históricas do seu papel diante da sociedade. Para Castells (FonteneleMourão, 2006), a redefinição do papel da mulher na modernidade está baseada, principalmente, em três fatores: a entrada maciça das mulheres no mercado de trabalho, o planejamento familiar por meio do controle reprodutivo com o advento da pílula anticoncepcional e a influência do movimento feminista. Diante desses aspectos, houve uma redefinição do lugar da mulher, que, antes, era restrito ao espaço privado, enquanto o espaço público era ocupado majoritariamente por homens.

A partir da compreensão de uma "nova mulher", fruto da atuação dos movimentos de mulheres, foi criado o Programa de Atenção Integral à Saúde da Mulher (PAISM) na década de 1980, demonstrando a necessidade de ampliação do olhar sobre a saúde da mulher que, até a década de 1970, era restrito à dimensão procriativa (Medeiros \& Guareschi, 2009). 0 PAISM trouxe a concepção de que a atenção à saúde não poderia se restringir a um determinado aspecto do sujeito, sendo necessário considerá-lo em sua integralidade.

No que tange à contemporaneidade, a mulher enfrenta dupla ou tripla jornada de trabalho relacionada à cobrança para que exerçam o papel de cuidadoras. A isso, associa-se o aumento da violência contra as mulheres em decorrência da divisão sexual do trabalho e, consequentemente, do poder doméstico. Essas peculiaridades atreladas às questões de gênero evidenciam a importância de considerar a especificidade dessa população no atendimento à saúde da mulher, a fim de proporcionar um cuidado integral.

Diante das mudanças no modelo de assistência do SUS e na concepção de saúde acerca da mulher, que passa a não se reduzir ao aparelho reprodutivo e a considera sujeito integral e com demandas específicas, a formação dos profissionais de saúde ainda está muito distante de corresponder ao que a realidade da assistência tem exigido. Pierantoni (2001) ressalta 
o distanciamento do setor educacional nas reformas no setor saúde, o que acarreta uma inviabilidade para os modelos propostos, ou seja, a inadequada formação de profissionais tem sido um obstáculo para as mudanças no modelo assistencial, já que os cursos de graduação e pós-graduação não formam o aluno para as necessidades do SUS. Com isso, há uma necessidade crescente de educação permanente para esses profissionais, com o objetivo de (re)significar seus perfis de atuação, para implantação e fortalecimento da atenção à saúde no SUS (Batista \& Gonçalves, 2011).

Com base nessas considerações, identificamos a importância de discutir como a formação acadêmica tem preparado profissionais para lidar com essas mudanças e novas exigências no campo da saúde, o que requer cada vez mais recursos da "caixa de ferramentas" do profissional de saúde ante a complexidade das necessidades de saúde e as nuances da singularidade de cada atendimento (Franco \& Merhy, 2005). Neste trabalho, atentaremo-nos à escuta como um desses recursos que possibilitam a integralidade do cuidado à mulher. Adotamos o termo "recurso" ao compreender que a escuta é algo que advém do profissional de saúde, não sendo, portanto, algo do campo externo do qual este decide fazer uso. Entende-se que isso não é dado, mas construído por meio da formação. Por isso, discutiremos sobre o papel da formação na saúde. Assim, elencamos como objeto de estudo o discurso dos profissionais de saúde em relação à escuta como um recurso terapêutico no cuidado à mulher.

Utilizaremos o termo (re)conhecer por entendermos que, diante da reflexão acerca dessa temática, alguns profissionais poderão reconhecer a escuta terapêutica na sua prática como um recurso utilizado, enquanto outros poderão conhecer a escuta, porém sem utilizá-la como um recurso terapêutico. Portanto, o objetivo do presente estudo é analisar o (re) conhecimento da escuta como recurso terapêutico pelos profissionais de saúde no cuidado oferecido às mulheres na Atenção Básica. O objetivo específico é registrar o entendimento dos profissionais de saúde sobre o reconhecimento da escuta às mulheres nas suas singularidades. Diante disso, pautamos este estudo na seguinte questão de pesquisa: os profissionais de saúde que atuam na Atenção Básica reconhecem a escuta como recurso terapêutico no cuidado à saúde da mulher?

Este estudo mostrou-se relevante por reconhecer a escuta como um recurso a ser utilizado no cotidiano das práticas de saúde, valorizando a sua capacidade de fomentar a pactuação entre a necessidade de saúde do usuário e a possibilidade de resposta do serviço, traduzida em qualificação da produção de saúde. Ao tomar por base essa compreensão, a escuta é um tema importante a ser estudado para que possamos refletir sobre a produção do cuidado integral oferecido à mulher na Atenção Básica e os entraves existentes à sua efetivação. Além disso, chama a atenção para a instrumentalização dos profissionais atuantes na Atenção Básica para realizar uma escuta que considere as questões de gênero um item importante a ser problematizado, a fim de dar visibilidade a essa temática e contribuir para a qualificação do serviço em saúde.

Além disso, esta pesquisa se enquadra na Agenda Nacional de Pesquisa na Saúde (Brasil, 2008), no que tange ao item "Sistemas e Políticas de Saúde" que traz como prioridade os estudos sobre modelos de atenção à saúde adequados às populações em condições diferenciadas, destacando-se os aspectos geográficos, comportamentais, de gênero e transgêneros; de avaliação sobre qualidade e humanização no atendimento, resolutividade dos níveis hierárquicos do SUS, acesso aos serviços de saúde e às ações de promoção, prevenção, 
recuperação e reabilitação; e sobre a Estratégia Saúde da Família: avaliação de impactos e sobre tecnologias de cuidado, orientação alimentar e inserção de novos profissionais na equipe. Diante dessas considerações, acredita-se que tal estudo seja relevante para a Agenda de Pesquisa em Saúde ao suscitar a reflexão acerca da prática profissional no campo da atenção básica em relação ao cuidado oferecido às mulheres. Dessa forma, pretende-se contribuir para a formação profissional no campo da saúde visando à qualificação da assistência prestada a mulheres usuárias da atenção básica, assim como trazer a discussão da influência das questões de gênero no cuidado em saúde.

\section{Método}

Para o presente estudo, optou-se por realizar uma pesquisa de caráter qualitativo, tendo como fonte primária de dados o discurso dos profissionais de saúde que atuam na Atenção Básica no Instituto de Atenção à Saúde São Francisco de Assis da Universidade Federal do Rio de Janeiro (HESFA/UFRJ). O HESFA, localizado no município do Rio de Janeiro, RJ, faz parte do Complexo Hospitalar da UFRJ. Os cenários de pesquisa para o presente estudo foram a Unidade de Cuidados Básicos (UCB) e o Centro de Saúde Escola São Francisco de Assis do HESFA/UFRJ, por serem dois campos de prática do Programa de Residência Multiprofissional em Saúde da Mulher, nos quais atuam profissionais da Atenção Básica.

A UCB é a unidade assistencial do HESFA responsável pelo atendimento ambulatorial que envolve ações de prevenção, promoção e recuperação da saúde em nível primário. Dentre os serviços prestados pelo setor, estão a enfermagem ginecológica, o acompanhamento psicológico, o tratamento de infecções sexualmente transmissíveis (ISTs), a cardiologia, a pediatria, a nutrição e a orientação psicossocial. A equipe de profissionais que atuam na UCB é composta de três médicos, seis enfermeiros, uma psicóloga, uma assistente social, um técnico de enfermagem e uma atendente, totalizando 13 profissionais atuantes nesse setor.

O Centro de Saúde Escola São Francisco de Assis atua na perspectiva da Estratégia Saúde da Família, sendo responsável pelo atendimento da população que reside na Comunidade do São Carlos e adjacências, pertencentes à área programática 1.0 do estado do Rio de Janeiro. A unidade é composta de três equipes formadas por um médico, um enfermeiro, um técnico de enfermagem e seis agentes comunitários de saúde em cada equipe. Foi inaugurado em 2011 e conta com 34 profissionais que atuam na unidade.

Ao considerar o objeto de estudo e os objetivos desta pesquisa, a entrevista individual semiestruturada foi escolhida como técnica de coleta de dados por permitir um contato direto com o entrevistado, possibilitando compreender o que ele pensa acerca do tema da pesquisa, além de proporcionar reflexões sobre o assunto. Para Gaskell (2008), na entrevista individual, considera-se a profundidade, sendo esta uma conversação um a um, uma interação díade. Sobre a entrevista semiestruturada, Manzini (2003) refere que é direcionada por um roteiro previamente elaborado que pode ser completado por outras questões ao longo da entrevista. Existe, assim, a possibilidade de livre troca de informações, não ficando condicionada a um padrão de perguntas.

O instrumento para a coleta de dados é o roteiro de entrevista semiestruturada criado para direcionar o presente estudo por meio de perguntas abertas, contendo uma questão 
de escala tipo Likert. Essa escala visa apontar o grau de concordância ou discordância do entrevistado em relação a um objeto de estudo, de acordo com o grau de intensidade, permitindo avaliar a atitude (Oliveira, 2001). Utilizaremos apenas uma afirmativa nesse modelo, buscando apreender a opinião dos profissionais quanto à escuta, analisando qualitativa e individualmente esse dado, articulando-o com o conteúdo da entrevista.

As entrevistas foram realizadas em uma sala reservada na UCB. O tempo de duração delas variou entre 20 e 40 minutos. Os participantes da pesquisa foram profissionais de saúde de nível superior que atuam diretamente no atendimento às mulheres usuárias dos serviços de saúde da UCB do HESFA e do Centro de Saúde Escola São Francisco de Assis, independentemente do tempo de formação e contratação, e que aceitaram o convite para participar da pesquisa mediante a assinatura do termo de consentimento livre e esclarecido (TCLE). $O$ critério adotado para interrupção da coleta de dados foi entrevistar todos os profissionais de nível superior que atuam na assistência à mulher nos setores mencionados. O estudo foi realizado de acordo com a Resolução no 466/2012, que trata de pesquisa com seres humanos. Esse estudo teve parecer aprovado para a sua realização em 22 de junho de 2016 pelo Comitê de Ética em Pesquisa da Escola de Enfermagem Anna Nery e pelo Instituto de Atenção à Saúde São Francisco de Assis da UFRJ (Cepe/EEAN/HESFA/UFRJ).

A técnica de análise de dados escolhida foi a análise de discurso francesa. Tal técnica tem como pressuposto a ideia de que a linguagem tem importância central na construção da vida social, não sendo um meio neutro de refletir ou descrever o mundo. Gill (2008) considera que a análise de discurso tem quatro temas principais: preocupação com o discurso em si mesmo; visão da linguagem como construtiva (criadora) e construída; ênfase no discurso como forma de ação; convicção na organização retórica do discurso.

No primeiro tema da análise de discurso, há preocupação dos analistas com o conteúdo e a organização dos textos, não havendo um enfoque no "o que estaria por trás", e, sim, nos textos em si mesmos. O segundo tema traz a noção de construção da linguagem, no sentido de que diferentes tipos de textos constroem o mundo. O terceiro tema realça o discurso/ linguagem como uma prática social, que não ocorre em um vácuo social empregado pelas pessoas para fazer coisas e que, para isso, orientam-se pelo contexto interpretativo em que se encontram. Por fim, o quarto tema diz respeito à abordagem da análise de discurso ao ver a vida social caracterizada por diversos conflitos, nos quais a linguagem possui natureza retórica, com o intuito de se tornar persuasiva, isto é, cada discurso traz uma visão de mundo que compete com a versão de outros discursos.

No que diz respeito à prática da análise de discurso, Gill (2008) orienta sobre alguns passos necessários à sua realização. Primeiramente, é preciso formular suas questões de pesquisa, pois, pelo fato de os analistas de discurso estarem interessados no texto em si mesmo, é interessante que sejam feitas diferentes perguntas. Após a escolha do texto a ser analisado, é preciso transcrevê-lo em detalhes, "a transcrição não pode sintetizar a fala, nem deve ser 'limpada', ou corrigida; ela deve registrar a fala literalmente, com todas as características possíveis da fala" (Gill, 2008, p. 251). Uma vez feita a transcrição, inicia-se uma leitura cética do material, ou seja, há suspensão da crença daquilo que é considerado dado e, em seguida, codifica-se o material estudado. Tendo completado a codificação, pode-se começar a análise. O importante é captar a marca linguística e relacioná-la aos contextos social e histórico.

Dessa forma, compreendemos que a análise de discurso auxiliará na abordagem ao 
discurso das participantes da pesquisa como falas integrantes de um contexto, sem perder a sensibilidade para os detalhes individuais de cada fala e, com isso, analisá-las como forma de estar-agir no mundo desses profissionais.

\section{Resultados e Discussão}

Foram entrevistados 16 profissionais que atuavam nos serviços. Os profissionais participantes da pesquisa pertenciam às seguintes categorias: médicos (5), enfermeiros (9), psicólogo (1) e assistente social (1). Para garantir a confidencialidade e assegurar o sigilo da identidade desses profissionais, todas as falas foram identificadas pela palavra "participante" seguida de um número. Empregou-se a codificação do material transcrito que resultou nas categorias apresentadas a seguir, relacionadas com objetivo deste trabalho. As categorias derivaram do agrupamento de palavras que mais apareceram no discurso dos participantes.

\section{Entendimento dos Participantes Acerca da Escuta na sua Prática Profissional}

Neste item, as categorias resultantes foram: "Acolhimento", "Vínculo"; "Empatia", "Comunicações verbal e não verbal" e "Compreensão integral".

Nas falas dos participantes, o "Acolhimento" esteve atrelado à possibilidade de oferecer um ambiente agradável, no qual as queixas do paciente são ouvidas, identificando-se suas necessidades, de forma que este se sinta à vontade e vincule-se ao serviço e ao profissional.

Quando a gente os escuta, eles se sentem mais acolhidos, eles se abrem mais. Eles acabam criando um vínculo com a gente. (Participante 11).

Tem que acolher muito bem para que ela volte, pois, às vezes, ela vem fazer o preventivo e nem volta para buscar o resultado. (Participante 6).

Só o fato de ter desabafado, falado e alguém escutou, parou de escrever e olhou para ela, já vê que já conseguiu acolher e já cria um vínculo maior com a pessoa, e aí vai ter mais abertura de falar até de outras coisas pertinentes até mesmo ali à conduta que você vai ter de acordo com o problema que ela apresente. (Participante 8).

Em consonância com o aporte teórico adotado para a análise dos dados, identificamos que a compreensão dos profissionais em relação à escuta como forma de acolhimento está de acordo com o que Merhy (1997) destaca ao considerar o acolhimento um componente do processo de criação de vínculo e do processo terapêutico. Para o autor, o acolhimento consiste na humanização das relações, nas quais os usuários e profissionais produzem uma relação de escuta e responsabilidade, constituindo vínculos e compromissos entre si. Dessa forma, percebe-se que escuta, acolhimento e vínculo são termos associados por serem recursos terapêuticos no cuidado em saúde.

O acolhimento foi citado e relacionado ao "Vínculo", em diversas falas dos entrevistados, como condição para estabelecer uma relação de confiança em que o paciente se sinta à vontade para falar e possa ser possível realizar a escuta. Diante disso, entende-se a confiança no profissional como um fator indispensável para que o paciente se vincule.

Você precisa deixar que a pessoa confie em você para chegar e abrir a alma, aí você consegue, às vezes, chegar ao submundo da alma. Então, eu acho que isso é muito 
importante, você cria um vínculo, esse vínculo emocional entre médico e paciente é muito importante. (Participante 7)

Primeiro que eles têm que conhecer o profissional para se sentirem à vontade. E aí gradativamente isso vai melhorando, porque eles vão se sentindo acolhidos, vão se sentindo tratados e aí parte dessas queixas vai acabando, porque eles são extremamente carentes. (Participante 16)

Essas falas reforçam o que Campos (2003) defende, trazendo a compreensão de que o vínculo, assim como a responsabilização e o acolhimento, faz parte do arsenal tecnológico da terapêutica e, por consequência, da clínica. Dessa forma, podemos dizer que a escuta está atrelada a esse pensamento, ao entender que o vínculo, a responsabilização e o acolhimento se constroem a partir da escuta. Matumoto et al. (2005) destacam que a mudança da lógica tradicional médico-centrada por uma prática assistencial em equipe voltada às necessidades da população tem como base de atuação o vínculo com a comunidade e a responsabilização dos profissionais pelas ações de saúde coletivas e individuais. Nesse sentido, é importante destacar que o vínculo estabelecido com o usuário, assim como o acolhimento e o significado que se dão na relação profissional-usuário, é apontado por Franco e Magalhães Jr. (2004) como fator importante para a resolutividade na rede básica, aliado ao recurso instrumental e ao conhecimento técnico dos profissionais.

Em relação a essa compreensão, os entrevistados destacaram a necessidade de se disponibilizar para o outro, ressaltando que isso requer investimento de tempo para escutar com atenção as demandas do paciente.

Você tem que estar disposto a ouvi-la sem pressa. (Participante 9)

Escuta é a capacidade que o profissional tem de parar, sentar, olhar, ouvir e depois fazer as interpretações, mas tem que ter olho no olho, com disponibilidade de tempo, paciência para ouvir, não pode ter pressa. (Participante 6)

Por meio das falas, percebe-se que os profissionais associam a escuta com o tempo de atendimento. Isso corrobora com a literatura, pois Lima (2014) destaca que "para que o sujeito fale, é preciso que o profissional esteja disposto a escutá-lo" (p. 342). Nesse sentido, a escuta passa pela questão do desejo, da disponibilidade interna do profissional em querer escutar o outro e também do tempo para fazê-lo. Atrelada a essa compreensão, alguns dos entrevistados pontuaram como entrave a grande demanda de pacientes a serem atendidos, o que muitas vezes impossibilita a prática da escuta.

Obviamente, a gente queria fazer uma coisa muito maior, de ter mais tempo de ouvir um pouco mais, mas infelizmente a rotina não permite, e aí a gente acaba escutando a queixa. (Participante 10)

É necessário que a gente perca um tempo com o paciente para ouvi-lo, porque em muitas das vezes são tantas as queixas que a gente se depara e a gente acaba vendo que parte dessas queixas são sintomas devido aos problemas que ele está vivendo e muitas das vezes vai se resolver com conversa, com papo, então eu acho que essa escuta é muito importante. (Participante 12). 
Acho que nessa escuta, como médica, tem que ser aprofundada, embora no PSF a gente não tenha muito tempo para isso. (Participante 7)

Diante dessas falas, podemos refletir que, embora haja valorização da escuta para a qualidade do atendimento, a dinâmica do trabalho leva os entrevistados a avaliar o uso do tempo destinado a escutar o paciente como "perda de tempo", pressionados pelo processo de trabalho que é composto de grande demanda de pacientes a serem atendidos. Nesse processo, percebe-se valorização do tempo em detrimento ao espaço dado ao paciente, evidenciando a não priorização da escuta como parte da ação de cuidado diante de um processo de trabalho pautado na produção. Vieira, Silveira e Franco (2011) enfatizam a necessidade de profunda transformação nos processos de trabalho em saúde, em que a fala e a escuta dos sujeitos sejam valorizadas como ponto de partida para as relações de cuidado.

Com base nas falas dos entrevistados, podemos perceber uma incongruência no que diz respeito à disponibilidade do profissional em escutar e nas impossibilidades do contexto ao qual o profissional está inserido. Nessa perspectiva, é importante pensar sobre a discrepância em relação à preconização do vínculo colocado como um dos princípios que norteiam a Atenção Básica (Brasil, 2012) e a realidade, que, por vezes, não permite a atuação pautada nesse princípio. No entanto, em meio a essa rotina de muitos atendimentos, percebemos que alguns profissionais mencionaram estratégias utilizadas a fim de realizar uma escuta voltada às necessidades do paciente, driblando os entraves existentes no contexto de atuação e buscando meios para exercer a escuta.

Eu tenho uma rotina de seguir uma avaliação, mas eu tento me manter um pouco aberta para ouvir mais e ir pegando os sinais que forem me passando para eu tentar no pouco tempo que é o que a gente tem por conta da demanda, para ouvir o máximo que eu puder. (Participante 10).

Eu acho que nessa escuta como médica, eu tenho que ir mais profundamente, embora no PSF a gente não tenha muito tempo para isso, a verdade é essa. Às vezes quando eu vejo que preciso ir muito mais a fundo então eu não perco essa cliente do meu contato. Hoje em dia eu percebo que eu posso ter um pouquinho hoje, amanhã posso ter mais um pouco, ai vou juntando os retalhos da colcha. Essa primeira escuta eu acho muito importante e eu gostaria que fosse até na primeira consulta, mas aqui pela nossa realidade porque são muitos clientes em um dia só então geralmente não é em uma primeira escuta. (Participante 7).

Com base na fala dos entrevistados, compreende-se que, em meio às impossibilidades do contexto de atuação dos profissionais, estes demonstraram capacidade criativa a fim de proporcionar ao usuário um cuidado de qualidade. Atrelado a esse entendimento, Bertachini (2012) destaca que a escuta tem como essência a valorização do outro, sendo necessário oferecer prontidão e tempo para acolher as demandas do paciente e suas particularidades.

No que diz respeito à "Empatia", os entrevistados destacaram que se colocar no lugar do outro é fundamental para entender o que o paciente está trazendo como demanda e, assim, compreender sua necessidade. Essa compreensão só é possível quando o profissional de 
saúde reconhece esse usuário como sujeito, o que pressupõe a valorização da alteridade e da relação sujeito-sujeito no cuidado em saúde. Para Campos (1997), não há construção de vínculo sem que o usuário seja reconhecido na condição de sujeito que fala, julga e deseja. Segundo Mesquita e Carvalho (2014), a humanização do cuidado em saúde depende da nossa capacidade de escutar a voz do outro e do diálogo com os nossos semelhantes, ou seja, estar frente a frente, "olho no olho", pessoa a pessoa constituindo uma relação de proximidade e afinidade. Nesse sentido, entende-se que perceber o usuário como semelhante é primordial para a humanização dos serviços de saúde.

Eu sempre me coloco no lugar da pessoa porque eu acho que se você não fizer isso, você não vai entender o problema dela, então é importante sairmos da posição de médico e nos colocamos como pacientes. (Participante 7)

Acho que se a gente começar a se colocar no lugar do outro, a gente começa a ter mais sensibilidade e, muitas vezes, acaba sendo resolutivo sem uso de medicamentos. (Participante 14)

A escuta também foi identificada como meio de exercer "comunicações verbal e não verbal", ou seja, um recurso que possibilita compreender o que o paciente necessita e, às vezes, não é mencionado como queixa. Portanto, é preciso acessar informações que "estão por trás da queixa" e, por meio da escuta, identificar as reais necessidades do paciente.

É escutar o que a clientela quer na realidade, porque às vezes elas vêm com uma queixa e não é aquilo. Eu trabalho, por exemplo, fazendo preventivo, mas às vezes não é isso que a pessoa está procurando. É outra coisa que ela está procurando e é nessa escuta, nesse momento que você para e entende o problema do paciente, você consegue inclusive ver o que ele realmente está precisando. (Participante 9).

A gente pode observar e ver o que pode ser feito para ajudar este paciente. Não necessariamente só pela dor que ele veio, por essa demanda e sim pelo que está por trás disso. (Participante 4)

Diante dessas afirmações, podemos confirmar o que Merhy (2002a) defende ao dizer que o cuidado começa na escuta, ou seja, é no espaço oferecido ao usuário, para falar e expor suas necessidades, que é possível produzir atos, ações, procedimentos e cuidados com os quais se pode chegar à cura ou a um modo qualificado de se levar a vida. Entende-se, portanto, que a escuta é um recurso utilizado a fim de acessar as necessidades do paciente e, assim, produzir cuidado. Às vezes, essas necessidades não são explicitadas de forma clara e direta, por isso os entrevistados destacaram que é necessário conhecer o que está "por trás da queixa", que são as reais necessidades do paciente.

Diante dessa questão, é importante diferenciarmos necessidade de saúde e demanda de saúde, que diferem pelo fato de a necessidade estar atrelada àquilo que o sujeito realmente precisa e, por vezes, não é explicitado, enquanto a demanda é aquilo que ele traz como uma questão a ser resolvida pelo serviço de saúde. Nesse sentido, entende-se que a escuta permite um cuidado ampliado ao possibilitar o acesso às necessidades de saúde do usuário e não somente a demanda. Essa compreensão é demarcada pelo Ministério da Saúde, ao enfatizar que para a atenção básica ser resolutiva, deve ter a capacidade ampliada de escuta 
(e análise), um escopo ampliado de ofertas para lidar com a complexidade de sofrimentos, adoecimentos, demandas e necessidades de saúde aos quais as equipes estão constantemente expostas (Brasil, 2013).

Ainda em relação à comunicação, os profissionais destacaram a importância de se atentar para o não verbal, trazendo um sentido ampliado para a questão da escuta que não se restringe ao discurso do paciente, mas atenta-se para o que se "fala" com o corpo, por meio de gestos, do olhar, do tom de voz etc. Esse entendimento é enfatizado por Mesquita e Carvalho (2014, p. 512) ao compreender a comunicação como componente importante da escuta terapêutica, envolvendo o entendimento do que a outra pessoa diz e sente. Segundo esses autores, a base da comunicação terapêutica é a relação estabelecida com o usuário, de modo que este utilize os seus recursos comunicativos (palavras, narrativas, expressões verbais e não verbais) para descrever sua história de vida e percepção de mundo.

A escuta pra mim tem que ser atenta. É estar atenta a tudo o que a mulher está falando e também ao que ela não está falando, às vezes por meio dos gestos, por meio dos olhares, às vezes por meio das palavras que não são claras. (Participante 13).

A escuta é a escuta da pessoa como um todo, na maneira de falar, no tom da voz, na postura, na fisionomia, nos gestos... então, tudo isso pra mim, está dentro da escuta. (Participante 3)

Os entrevistados ressaltaram também que a escuta é um recurso que possibilita "compreensão integral" do usuário, trazendo a concepção da saúde de forma ampliada, que não se restringe à doença orgânica, destacando a importância de escutar o que o paciente traz em relação à vida, ao seu contexto etc. Esse olhar ampliado sobre o sujeito está intimamente ligado ao conceito de integralidade que considera as dimensões biológica, psicológica, cultural e social do usuário, orientando políticas e ações de saúde capazes de atender às demandas e necessidades da população (Pinheiro, 2009). Segundo Mattos (2006), tal integralidade implica recusa ao reducionismo, à objetivação dos sujeitos e, talvez, uma afirmação de abertura ao diálogo. Percebe-se, portanto, que os profissionais têm o entendimento desse conceito e trazem essa compreensão no seu discurso.

É estar pronto a ouvir o que ele tem a falar, da queixa dele, de tudo, da ponta do fio de cabelo à unha. É qualquer coisa relacionada à saúde como também da vida pessoal, do trabalho, da família... Tudo o que tiver relacionado ao bem-estar, né? (Participante 16)

É um cuidado bem minucioso dessa mulher, um cuidado integral, porque não é só olhar a paciente como um sistema reprodutor feminino, como uma vagina, como um colo uterino, como uma mama, mas como um todo. (Participante 15)

\section{Reconhecimento da Escuta como Recurso Terapêutico}

Solicitamos aos participantes que marcassem, em uma escala de 1 a 5, o reconhecimento da escuta como um recurso terapêutico em sua prática profissional. Todos os participantes, sem exceção, marcaram o grau máximo na escala. Eles explicitaram mudança perceptível na forma como o paciente chega à consulta e como sai desta ao ser escutado pelo profissional de saúde. 
Deixar a pessoa falar é o mais importante e isso tem efeito terapêutico sim. Normalmente as pessoas saem melhores do que entraram só pelo fato de falar. (Participante 2)

Você vê que às vezes ela entra com uma feição e sai com outra bem melhor, só pelo fato de ter falado. (Participante 11)

Ela sai mais aliviada, porque eu escutei. A escuta por si própria já alivia. (Participante 7).

Assim, percebemos que a escuta é entendida como um meio de atenuar as angústias do paciente, ao oferecer um espaço para que este exponha as suas questões, sendo esta uma compreensão destacada por Campos (2003), ao colocar a intervenção terapêutica como parte "essencial da clínica que estuda e põe em prática meios adequados para curar, reabilitar, aliviar o sofrimento e prevenir danos futuros" (p. 68). No entanto, por meio das falas dos profissionais, percebemos que estes não reconhecem a escuta como uma intervenção, sendo colocada de forma simplificada e reduzida ao mencionarem que "só" escutaram o paciente ou não reconhecem essa escuta como parte integrante da consulta.

A pessoa vai embora, e nem faz a consulta, não toma remédio, nada e sai satisfeita. (Participante 4)

Em diversos atendimentos eu percebo isso, que as pessoas vêm só para falar e não necessariamente porque estão doentes ou precisando de uma intervenção. E no final elas dizem "Já saí daqui aliviada, estou saindo melhor" e ela só falou. (Participante 13)

A pessoa se sente atendida na necessidade dela, mesmo que essa necessidade não seja expressa verbalmente, ela vem com uma série de emoções tipo carência, e aí só o fato de escutar, como olhar também, normalmente tem um efeito, eu percebo isso. (Participante 5)

Diante disso, entende-se que os profissionais percebem o resultado terapêutico da escuta no paciente, mas não a identificam como um recurso a ser utilizado para produzir cuidado. Essa compreensão é dissonante ao que Franco e Magalhães Jr. (2004) propõem sobre um processo de trabalho centrado nas tecnologias leves e leve-duras como condição para que o serviço seja produtor do cuidado. No entanto, no cotidiano dos serviços de saúde, ainda há a prevalência das tecnologias duras em detrimento das tecnologias leves (das relações). Merhy (2002a) destaca que o desafio que se coloca é a transformação da atenção sanitária centrada no procedimento em uma atenção centrada no usuário. Isso requer inversão das tecnologias de cuidado a serem utilizadas na produção da saúde. Segundo essa perspectiva, destacamos algumas falas nas quais os profissionais fazem um comparativo da escuta em relação ao exame físico.

É melhor você ter uma boa escuta do que às vezes você ter um exame físico, porque uma boa história leva você a fazer um bom diagnóstico, mais do que, às vezes, um exame físico. (Participante 5)

É fundamental o papel da história na avaliação do paciente, no sentido, dele te contar as queixas. É $90 \%$ do diagnóstico e às vezes mais e às vezes um pouco menos de acordo com a doença. O exame físico traz muito pouco. (Participante 2)

Percebemos que os profissionais destacaram a importância de escutar a história do paciente para construir uma conduta terapêutica resolutiva. Por meio do discurso dos profissionais, 
entende-se que a escuta é colocada como um recurso que auxilia no diagnóstico, não sendo identificada em si como intervenção em saúde. Atrelada a essa compreensão, identificamos algumas falas dos entrevistados que demarcam a contraposição da escuta em relação à prescrição médica, evidenciando o pensamento dicotômico dos profissionais acerca da escuta no contexto do atendimento de saúde.

Eu acho que em muitos casos é fundamental [a escuta]. Claro que o paciente também precisa da medicação. (Participante 12)

Às vezes também a escuta pode resolver o problema, mas não sozinha também, porque às vezes tem que entrar com medicação querendo ou não. Às vezes é só um problema familiar e aí só ouvindo resolve. Às vezes o problema familiar levou a uma depressão. Aí tem que entrar com medicação, então depende do caso. (Participante 16)

Dessa forma, entende-se que há a concepção do uso de um recurso em substituição de outro, não havendo a compreensão da escuta como parte integrante do aparato tecnológico de cuidado do profissional de saúde. Diante dessa concepção, percebe-se que os profissionais conhecem a escuta e o resultado que esta proporciona, no entanto não a reconhecem como recurso integrante da prática profissional.

Entre as falas dos profissionais, destacou-se a compreensão da escuta como terapêutica por possibilitar a identificação das reais necessidades do paciente, seja de ordem física, psicológica ou social, por meio do estabelecimento de uma relação dialógica com o usuário, considerando o contexto em que este está inserido. Diante dessas considerações, percebe-se que a escuta detém um papel importante na construção de uma relação terapêutica entre profissional e usuário. Com isso, é possível realizar um cuidado pautado na identificação das necessidades e problemas da pessoa escutada para o planejamento das ações em saúde (Souza et al., 2003). Portanto, a escuta é um recurso dos profissionais de saúde que cuidam e o interesse maior não é na narrativa pronta, mas no que esta traz para reconhecer as necessidades e demandas desse sujeito.

A escuta é um recurso terapêutico muito valioso. Porque é a partir da escuta que você vai conhecer a paciente e vai saber quais são as necessidades que ela tem e como direcioná-la. (Participante 15)

Não é o fato de você estar ali parada, acompanhando o que a pessoa está dizendo que significa que você está fazendo uma escuta terapêutica. Você pode estar só ouvindo, mas não está fazendo de fato uma escuta, porque você não está considerando todos os fatores, todo o contexto no qual aquela pessoa está inserida. (Participante 3)

\section{Reconhecimento da Singularidade do Atendimento à Mulher}

Ao serem questionados se concordavam com ou discordavam da afirmativa "A escuta é um recurso terapêutico no atendimento à saúde da mulher", todos os entrevistados concordaram e enfatizaram que a escuta deve ser inerente a todos os usuários e não somente às mulheres.

Sei que a sua pesquisa é mais para a saúde da mulher, mas escutar o doente é muito fundamental para todos. (Participante 12). 
Em minha opinião ela é importante em todos para todos os grupos, faixas etárias, enfim acho muito importante como um modo terapêutico para que as pessoas tenham um espaço de falar, ter um espaço de colocar as coisas que às vezes ela não consegue falar com um amigo, com um familiar ou com ninguém e aí com o profissional de saúde ela vai ter essa possibilidade. (Participante 13).

Diante dessas falas, percebe-se o reconhecimento da importância da escuta para o cuidado em saúde de todos os usuários, enfatizando que esse recurso deve ser utilizado em todo e qualquer atendimento. Essa compreensão nos faz pensar que os entrevistados entendem que a escuta não deve ser destinada a apenas um público específico - já que enfatizamos o cuidado oferecido às mulheres neste estudo -, destacando, assim, a importância da escuta para todos os usuários.

Alguns profissionais enfatizaram que não há diferença na escuta no que diz respeito ao gênero da pessoa que está sendo atendida. Percebe-se que os profissionais salientaram não haver diferenciação em relação ao gênero, no intuito de caracterizar igualdade no cuidado oferecido tanto para homens quanto para mulheres.

Eu não consigo separar e ver essa diferença entre a escuta para o homem ou a escuta para a mulher. Não consigo fazer essa separação não. (Participante 15).

Mas a minha maneira de escutar, independente de ser mulher ou homem, seria a mesma. Eu escuto os dois da mesma maneira. Não tem nenhuma peculiaridade por ser muIher, da minha parte profissional. (Participante 6).

Com base nas falas dos profissionais, podemos dizer que essa não diferenciação em relação à escuta dos homens e das mulheres traz a compreensão de igualdade no atendimento visando à não discriminação. No entanto, pontuamos a necessidade de considerar as especificidades da população atendida, trabalhando com um dos princípios do SUS que é a equidade. A noção de equidade diz respeito à necessidade de "não tratar desigualmente os desiguais", de modo a alcançar a igualdade de oportunidades de sobrevivência, de desenvolvimento pessoal e social entre os membros de uma dada sociedade (Teixeira, 2011). Diante dessa compreensão, entende-se que é preciso reconhecer a desigualdade entre as pessoas e os grupos sociais, assim como as injustiças que devem ser superadas. Nesse sentido, compreende-se que a igualdade só é possível quando consideramos as diferentes necessidades dos usuários. Portanto, é preciso considerar as especificidades da população feminina, a fim de produzir um cuidado pautado nas necessidades dessa população, buscando, assim, a equidade da atenção à saúde.

Algumas falas dos entrevistados enfatizaram esse aspecto ao mencionar questões que permeiam a vida das mulheres, trazendo o entendimento da necessidade de um cuidado integral diante da singularidade dessa população. Com base nas falas, percebe-se que as questões de gênero atravessam a vida da mulher que busca atendimento de saúde e, por isso, é importante que sejam consideradas, a fim de proporcionar um cuidado integral que considera o contexto e a singularidade da usuária.

Segundo essa perspectiva, Coelho et al. (2009) destacam a importância de o cuidado em saúde ser pautado no acolhimento com escuta sensível às demandas, considerando a influência das relações de gênero no processo de saúde e adoecimento. Dessa forma, entende-se que a integralidade e a perspectiva de gênero precisam repercutir nas práticas de 
saúde, "desde o acolhimento até a recuperação de homens e mulheres, condições sine qua non para a humanização e qualidade da atenção à saúde que implicam o estabelecimento de relações entre sujeitos" (Souto, 2008, p. 176).

A mulher tem diversas questões. Tem aquela mulher que quer fazer um aborto, ou aquela que sofreu algum tipo de violência, ou aquela mulher que não aguenta mais trabalhar para ter que sustentar o filho sozinha, então tem coisas específicas da mulher que são mais duras ou talvez mais cruéis comparado com outras coisas. (Participante 13)

A mulher vive diversas dificuldades por conta da sociedade que a gente vive, da subjulgação que a maioria delas. É de uma submissão, "Ah, ele não quer, então não". E a minha vontade? E o meu desejo? O que eu quero? Onde fica? Eu nunca? Só o outro? Porque qualquer pessoa que não expressa os seus desejos, que não faz aquilo que também quer em algum momento a cabeça vai ficar ruim. (Participante 12).

Ainda segundo a compreensão das questões específicas da população feminina, outro aspecto que permeou o discurso dos profissionais foi o papel social da mulher e as suas implicações no cotidiano e, até mesmo, na sua saúde. Ficou marcado nas falas o papel da mulher como cuidadora, sendo ela a responsável pelo cuidado da família, confirmando o que a Política Nacional de Atenção à Saúde da Mulher (Brasil, 2004) sinaliza.

Antes a mulher era uma dona de casa, mas hoje ela faz muitas mais coisas, hoje em dia ele tem que ser dona de casa, ela tem que trabalhar, agradar o marido, estar bonita e cheirosa tudo isso junto e o homem Alguns já estão ajudando a mulher nos afazeres de casas, mas existem muitos ainda que são machistas, que trabalham e acham que a muIher mesmo trabalhando chega em casa e tem que fazer tudo e dar na mão dela. Ainda persiste esse modelo. (Participante 7).

A mulher deixa a vida dela de lado. Vive para todo mundo menos para ela mesma. Até me relação ao seu cuidado mesmo. Ela tem tempo para trazer cinco filhos para a puericultura, mas ela não tem tempo de fazer um preventivo, porque ela tem que arrumar a casa, levar o filho na escola, tem que fazer muita coisa e acaba banalizando um pouco a saúde dela para cuidar dos outros. (Participante 10).

Com base no discurso dos entrevistados, é possível constatar que há a compreensão dos profissionais acerca de uma escuta diferenciada ao público feminino por todas as questões do "ser mulher" nos dias de hoje, diante do papel social que esta exerce. No entanto, pouco se percebeu nas falas dos profissionais a implicação que essas questões podem trazer para a saúde da mulher, o que nos faz refletir sobre a necessidade de capacitação específica para os profissionais de saúde acerca das questões de gênero e sua relação com a saúde.

\section{Abordagem do Tema da Escuta na Formação}

Diante das demandas da atualidade, destaca-se a necessidade de discutir como a formação acadêmica tem preparado profissionais para lidar com essas mudanças e novas exigências no campo da saúde. Com isso, exigem-se cada vez mais recursos da "caixa de ferramentas" de quem atende ante a complexidade das necessidades de saúde e as nuances da singularidade de cada atendimento (Franco \& Merhy, 2005). 
Entre os entrevistados desse estudo, nove eram enfermeiros, cinco médicos, um assistente social e uma psicóloga. Identificamos certa heterogeneidade em relação ao tempo de exercício da profissão dos entrevistados, pois, entre os enfermeiros, variou de um a trinta anos, assim como entre os médicos (de um a quarenta anos). O tempo de formação da assistente social e da psicóloga foi de 13 e 20 anos, respectivamente.

No que diz respeito à abordagem da escuta na formação dos profissionais entrevistados, três enfermeiros e três médicos responderam que esse assunto não foi abordado na formação. Dentre os que disseram que a escuta foi abordada na formação, três enfermeiros e dois médicos mencionaram que foi apenas na graduação, enquanto três enfermeiros, um médico, um assistente social e uma psicóloga destacaram que a escuta foi abordada na graduação e na pós-graduação.

Com base nos dados descritos anteriormente, percebemos que a escuta foi abordada na formação da maioria dos profissionais entrevistados. No entanto, no que se refere às experiências de aprendizagem em relação a essa temática, percebemos que a escuta pouco foi valorizada como recurso importante na prática clínica, sendo, por vezes, vista como algo irrelevante. As seguintes falas destacam esse aspecto:

Na graduação, talvez tenha sido abordada, mas assim, não tendo a importância que ela deveria ter. Passou... (Participante 6)

[A escuta] foi abordada no sentido de fazer parte da propedêutica, do estudo do paciente para fazer um diagnóstico, mas não em termos de uma pessoa que vem falar das coisas dela com você. Até mesmo na Psicologia Médica, porque quando você tem que colocar uma especialidade para te dar aula sobre o assunto, já é uma maneira de você dizer assim 'Isso aqui é um negócio que você pode esquecer. É uma invenção de meia dúzia, mas isso na realidade não é verdade. Aliás, mesmo que seja verdade, pouco importa. É uma coisa que temos que te ensinar, mas pode esquecer'. Isso é uma coisa transdisciplinar, devia ser visto em todas as disciplinas que a gente estuda. (Participante 5)

Dentro da Medicina, essas outras questões não foram abordadas. Eu acho que isso falta na formação do médico. E se você parar para escutar o paciente, muitos reclamam da falta de escuta do médico. (Participante 12)

As falas dos entrevistados também evidenciaram a vinculação da escuta ao campo da Psicologia ao relatarem as suas experiências de aprendizagem acerca desse tema. Entende-se que os profissionais associam a escuta a um recurso que pertence ao campo da Saúde Mental e, por isso, relacionaram o aprendizado desse recurso às disciplinas desse campo de saber.

Faz muito tempo que eu me formei, mas eu tive Saúde Mental em todos os períodos da faculdade. Então, eu acredito que a escuta foi abordada na formação sim. (Participante 1)

Ela estava chorando e aí eu a ouvi, conversei, mas era paciente psiquiátrica. Aí acaba que a gente cai de novo nessa questão da Psiquiatria. Mas ela vem aqui quase todo dia e sempre está chorando, sempre tem uma queixa, entendeu? Talvez ela precise ser ouvida (Risos). (Participante 16).

Nesse sentido, entende-se que a escuta é reconhecida como pertencente a um campo específico e, portanto, não está na alçada do campo da saúde como um todo. Essa compreensão 
reflete, mais uma vez, a resistência em fazer uso de um recurso que é da "caixa de ferramentas" de um outro campo de saber, reforçando a falta de integração entre as especificidades. Isso fica evidente nas seguintes falas:

O processo terapêutico desse tipo de distúrbio de ansiedade, de depressão, não é com a gente, mas é mais com a Psicologia que toma a frente disso, que é basicamente ouvir, para haver a associação de ideias, buscando iluminar aquelas áreas do oceano que o paciente não consegue ver. (Participante 5).

A enfermagem deixa você muito prática. Você vai lá, faz o procedimento, você faz, você atende. E na saúde mental não tem essa nossa prática, é escuta mesmo, é avaliação da situação e escuta do cliente com suas dificuldades e da família. (Participante 12).

No discurso dos profissionais, percebe-se a rigidez entre os campos de saberes, não havendo confluência entre os diferentes modos de fazer saúde. Essa postura contrapõe-se ao que a Política Nacional de Humanização preconiza ao trazer o conceito da Transversalidade, que, segundo Pedroso e Vieira (2009), significa colocar os saberes e práticas de saúde no mesmo plano comunicacional, provocando a desestabilização das fronteiras dos saberes, territórios de poder e modos instituídos nas relações de trabalho, para a produção de um plano comum. Nesse sentido, entende-se a importância da interlocução de diferentes saberes, buscando apreender variadas ferramentas para a sua "caixa", a fim de possibilitar um cuidado mais integral.

Outro aspecto destacado pelos entrevistados foi quanto ao modelo de saúde, explicitado nas falas no reconhecimento de a formação ser voltada para a doença, para realização de diagnósticos, não valorizando um olhar voltado para o sujeito e seu contexto. Destacamos duas falas de profissionais que se formaram recentemente e retratam essa questão, sinalizando que a formação ainda é pautada no Modelo Biomédico e, por isso, não privilegia a prevenção de doenças nem a escuta, por exemplo, como foi mencionado pelos entrevistados.

Pra gente que é médico aqui no Brasil fomos treinados a passar medicação pra resolver tudo, diferente de outros lugares. Não sei como é hoje em Cuba, mas lá é bem voltado para Medicina Preventiva e não ficam só na medicação. (Participante 16 - formado há um ano).

Quando aprendemos a escuta não seguimos um modelo biomédico, de que é só dar um diagnóstico e passar medicação, mas é tentar entender o que está por trás daquele diagnóstico, compreender o contexto através da escuta. (Participante 14 - formada há dois anos).

Diante disso, percebe-se que mesmo com a proposta da Atenção Básica de proporcionar ao usuário um cuidado integral, tendo como premissa a ampliação dos modos de pensar-fazer saúde, ainda há o predomínio do modelo tradicional biomédico na formação profissional. Essa questão corrobora o que foi mencionado por Pierantoni (2001) ao ressaltar o distanciamento do setor educacional das reformas no setor saúde como um fator que acarreta a inviabilidade dos modelos propostos. Diante disso, entende-se que a inadequada formação de profissionais tem sido um obstáculo às mudanças no modelo assistencial, já que os cursos de graduação e pós-graduação não formam o aluno para as necessidades do SUS. 
Os profissionais também ressaltaram que a formação não valorizou a escuta de forma efetiva e, por isso, as experiências de aprendizagem não foram eficazes. Nas falas a seguir, percebemos que a escuta não é colocada como uma habilidade importante a ser aprendida e exercitada pelo profissional de saúde, sendo abordada apenas de forma superficial.

Eu estou fazendo pós em saúde da família. Comecei a fazer semestre passado e ainda não foi abordado não. Não falaram nada sobre escuta ativa. Eles até falam, mas muito rápido, falam que é importante ter, mas ninguém chega assim para desmembrar, detaIhar, essas coisas. (Participante 4)

Eu me lembro que nos primeiros estágios que a gente chega ao hospital os professores falam isso que é importante escutar, mas não explicam o que é escuta, que não é só você ouvir, é você se atentar, você observar o que está por trás do que ele está falando, essas coisas todas. (Participante 14)

Com base nas falas citadas, percebemos que a escuta é abordada apenas no nível teórico, de forma que não há a compreensão do "como fazer", a fim de trazer o entendimento da prática da escuta como um recurso na atuação profissional. Diante disso, podemos refletir sobre a eficácia das estratégias de ensino-aprendizagem que estão sendo utilizadas na graduação e na pós-graduação.

Alguns entrevistados mencionaram algumas experiências de aprendizagem, sempre remetendo à questão da vivência prática, trazendo exemplos do contato com o paciente e dos estágios realizados, destacando que o aprendizado se deu no contato com o campo de atuação. As falas seguintes retratam esse aspecto:

O estágio no hospital psiquiátrico, foi extremamente marcante. Porque ali você lida com escuta muito fora da realidade, então aprendi muito como escutar, mesmo quando não faz o menor sentido àquilo que está sendo dito e conseguir dali compreender esse sujeito, o que ele está passando, que sofrimento é aquele, mesmo não tendo a menor lógica aquilo que ele está falando. (Participante 3).

Quando eu fiz o curso de facilitadores de educação permanente, a gente teve que fazer algumas atividades na prática, então você aprende a ouvir, foi um curso de aperfeiçoamento e a questão da escuta foi muito abordada. (Participante 13).

Com base nessas falas, evidencia-se a valorização dos profissionais em relação às vivências, demonstrando que as experiências no campo prático foram o que mais demarcou o aprendizado acerca desse tema. Dessa forma, entende-se que o contato com atividades vivenciais é potente, no que diz respeito à escuta, para a aprendizagem dos alunos. Essa questão foi demarcada nas falas dos entrevistados ao relatarem experiências na formação, nas quais foram realizadas vivências no contexto de aprendizagem, sendo vista de forma positiva pelos profissionais.

Eu lembro que a professora na época, isso há muitos anos atrás, a gente tentava vivenciar, a gente criava situações em relação ao enfermeiro e o paciente e as colegas da turma tinham que avaliar, escrever. Eu lembro muito disso e era muito legal. (Participante 4).

A gente fazia um internato e nós tínhamos uma salinha, porque a Saúde Mental nos últimos períodos era 'Vivendo vivências' e aí a gente ia para essa salinha, todo mundo 
sentava no chão e aí a gente falava das nossas experiências para saber trabalhar com aquilo porque a gente acaba levando o paciente pra casa, porque não está acostumado com aquilo e vai carregando tudo. Era um momento para a gente conseguir separar, de colocar pra fora, de conseguir trabalhar isso e era muito bom. Eu fazia questão de ir. Nossa! Eu fazia questão que fosse todo mundo. (Participante 1).

A questão da prática foi um aspecto mencionado como aquilo que produziu a compreensão e o conhecimento acerca da escuta, tanto no contexto de formação como na atuação profissional. Alguns entrevistados destacaram que a escuta não foi abordada na formação, sendo, portanto, necessário aprender sobre essa temática no exercício profissional.

A formação em si não me instrumentalizou para essa questão da escuta, só me despertou para a importância, mas a prática que foi importante e que me fez exercer isso. (Participante 15).

Não tive [experiência de aprendizagem]. Em estágio de Medicina é assim: Entra e atende (ênfase na fala). Isso é estágio de Medicina (Risos). Então não tem muito isso. . . Mas eu acho que a gente vive aprendendo todos os dias, e aí na sua vida você vai ver coisas boas e ruins e aí você vai filtrar o que você quer pra você. Como é que é a sua prática? o que você interpreta como boa prática? E aí vai utilizando. (Participante 12).

Até mesmo aqueles que demarcaram a discussão da escuta na sua formação ressaltaram a prática como essencial para compreender esse recurso. Por meio do discurso dos participantes, é possível perceber a valorização da atuação profissional como aquilo que proporciona sentido para o que é aprendido na teoria.

Foi abordada, com certeza. O que mais se falava era sobre escuta. Mas só na prática que a gente começa a entender que escuta é essa (risos). (Participante 3)

Na pós-graduação, não é que eu tenha ouvido mais, mais ficou mais marcado, conforme também eu já estava no serviço, já estava atuando como profissional, então eu já estava fazendo uma relação da teoria e a prática. Na graduação você vê mais a teoria, mas aí você vai aprimorando mais com a prática também. (Participante 13)

Diante disso, é importante enfatizar a necessidade de a formação profissional valorizar o aprendizado baseado na prática, trabalhando conceitos da saúde aplicados na prática. É no campo de atuação que o profissional se depara com as possibilidades e impossibilidades do seu fazer. Segundo Paim (1993), é o serviço, em sua realização concreta, que pode permitir a demonstração de que o contexto social e econômico não é externo ou alheio à Saúde ou à Medicina (um envoltório como aparece nos esquemas), mas intrínseco e mediador em todas as práticas. Portanto, é na prática da assistência que é possível compreender a multiplicidade de fatores que influenciam diretamente o cuidado em saúde, possibilitando, assim, que o profissional em formação considere esses diferentes aspectos em sua atuação.

Os entrevistados também consideraram a escuta uma tendência própria do profissional de saúde, sendo, assim, uma habilidade própria da personalidade do sujeito. As falas dos entrevistados demarcaram a compreensão da escuta como algo intrínseco ao indivíduo.

Eu tenho a tendência a escutar mesmo, acho que é uma questão de personalidade. (Participante 2). 
Eu acho que isso é uma característica minha. Independente da formação profissional. Porque eu vejo pessoas que fizeram na mesma época que eu fiz e não são iguais, então eu acho que é do profissional mesmo. (Participante 15)

Acho que não só a minha faculdade, eu acho que o meu jeito mesmo sempre me possibilitou ter uma escuta muito ativa com os pacientes, eu costumo realmente escutar e tudo mais. (Participante 4)

Nesse sentido, é importante pensarmos sobre essa compreensão que os entrevistados trouxeram, remetendo a escuta à personalidade, a uma disposição própria do indivíduo. No entanto, precisamos entender que a escuta é um recurso da prática profissional, logo é aprendida e exercida com base na apreensão do conhecimento ao atuar no cuidado em saúde. Diante dessa questão levantada pelos entrevistados, percebemos que é importante desconstruir essa compreensão da escuta como algo intrínseco, que pode se configurar como um entrave à aprendizagem desse recurso.

\section{Considerações finais}

Com a mudança da lógica tradicional médico-centrada por uma prática assistencial em equipe voltada às necessidades da população que a Atenção Básica preconiza, propõe-se uma atuação baseada no vínculo e na corresponsabilização. No entanto, percebe-se uma dissonância entre o que é preconizado pelas Políticas Públicas e o que é demandado ao profissional no contexto de atuação, exigindo quantitativos de atendimentos em detrimento da qualidade da assistência. Diante dessa discrepância, percebe-se que o profissional de saúde fica ambivalente entre valorizar o tempo e a produção de atendimentos ou a escuta ao usuário, a fim de proporcionar um cuidado integral. Nesse sentido, fica a cargo do profissional optar por uma conduta valorizada nas políticas de formação em saúde, mas negligenciada na dinâmica dos serviços de saúde. Com isso, emerge a busca por estratégias criativas diante de um processo de trabalho que dificulta e não valoriza a escuta, exigindo do profissional a construção de meios e recursos diante desse contexto ante os preceitos da Atenção Básica.

$\mathrm{Na}$ análise das entrevistas, cabe ressaltar o discurso dos profissionais sobre o conhecimento destes em relação à escuta como conceito. Todos a valorizam e conhecem-na, no entanto, percebe-se que a escuta foi (re)conhecida e valorizada como um recurso terapêutico na atuação profissional, de forma empírica, sem a prática vivenciada, significada e específica. Diante disso, podemos pensar quais estratégias de aprendizagem estão sendo utilizadas na formação do profissional para capacitá-lo ao exercício de uma escuta realmente efetiva como preconizado pelas políticas públicas. Sendo assim, é preciso que a formação busque ensinar o "como fazer", trabalhando com o estudante a prática dessa ferramenta no cotidiano da assistência. Enfatizamos, assim, a necessidade da formação em saúde reconhecer, valorizar e capacitar profissionais que identifiquem a escuta como recurso terapêutico, oportunizando o exercício da escuta no processo formativo, por se tratar de um recurso aprendido.

Em relação à valorização da escuta, percebe-se que os profissionais reconhecem o resultado que a escuta proporciona no cuidado em saúde, sendo um recurso que possibilita acessar a necessidade do usuário, atenuar angústias e sofrimentos, assim como construir uma terapêutica mais eficaz. Contudo, não há o (re)conhecimento da escuta como uma forma de 
intervenção em saúde, sendo, por vezes, colocada como algo que não faz parte da consulta. Diante disso, percebemos que essa incongruência entre a valorização desse recurso e a inclusão da escuta nas práticas de saúde é uma questão a ser problematizada com os profissionais de saúde, por meio da Educação Permanente, possibilitando que estes reflitam sobre as suas práticas e incorporem esses recursos à assistência ao usuário.

Um aspecto destacado nos resultados foi a compreensão da escuta como um recurso pertencente a um campo de saber específico, sendo relacionado à atuação da Saúde Mental, assim como o campo teórico correlacionado a essa especificidade. Com base nesse achado, podemos refletir sobre a relação existente entre o modelo de atenção e de formação profissional, pois esse discurso está atrelado à compreensão pautada no pensamento cartesiano cuja premissa é a dicotomia mente-corpo. Nesse sentido, percebe-se que a formação em saúde ainda não está pautada na compreensão integral do sujeito e esse pensamento orienta a prática profissional e repercute em atenção fragmentada ao usuário, independentemente da especificidade. Nessa perspectiva, a Residência Multiprofissional em Saúde tem uma contribuição a dar, levando ao campo de atenção práticas de interconsultas e consultas conjuntas, que incluam todos os profissionais envolvidos no cuidado ao usuário na prática da escuta.

Em relação à compreensão dos profissionais sobre as questões de gênero e suas implicações na saúde, percebe-se que os entrevistados (re)conhecem as diversas questões relacionadas à mulher. No entanto, não trazem esses aspectos atrelados à saúde da mulher e, portanto, não consideram a especificidade do atendimento a essa população. Diante dessa compreensão que os profissionais trouxeram em relação às questões atreladas ao gênero, podemos destacar a importância da Educação Permanente nesse contexto, a fim de que os profissionais reflitam sobre as especificidades de cada população e suas implicações na saúde.

Ainda em relação ao gênero, destaca-se, por meio desse estudo, a influência do gênero nas relações como um todo, até mesmo entre profissional e usuário, sendo este um aspecto ressaltado pelos entrevistados e percebido como um fator que interfere na relação terapêutica e, por conseguinte, no cuidado em saúde. Diante disso, percebemos que essa temática precisa estar presente no processo de formação dos profissionais de saúde, a fim de haver uma reflexão acerca da importância de se considerar as questões de gênero no cuidado em saúde, assim como as implicações do contexto e da sociedade em que estamos inseridos.

Por meio da análise dos resultados, percebemos que o estudo possibilitou a reflexão sobre esse tema com base na entrevista realizada com os profissionais de saúde, sendo um meio de sensibilização do entendimento e valorização da escuta como recurso terapêutico. Essa compreensão ocorreu diante da percepção da mudança do discurso no decorrer da entrevista e, no final, todos os profissionais enfatizaram a escuta como um recurso terapêutico no cuidado à saúde da mulher. Tomando isso por base, entende-se que esta é uma questão latente, sendo necessário haver um espaço de reflexão entre os profissionais sobre as suas práticas, visando, assim, enriquecer a atuação em saúde por meio da compreensão, discussão e instrumentalização de recursos e ferramentas para um cuidado integral e resolutivo.

Como desdobramento do estudo, pode-se sugerir que as ações cujo objetivo seja sensibilizar e capacitar profissionais de saúde para uma escuta qualificada incluam os agentes comunitários de saúde, que atuam diretamente no acolhimento das mulheres que acessam o serviço de Atenção Básica. Além disso, o gestor da unidade de saúde também pode 
contribuir com uma visão da gestão da assistência que valorize e reforce a compreensão da escuta como recurso terapêutico.

Por meio desse estudo, foi possível evidenciar a necessidade imperativa de a Educação Permanente fazer parte do cotidiano dos profissionais de saúde por tratar-se de um recurso de aprendizagem que possibilita ressignificar as práticas em saúde e promover a adequação dos perfis de atuação dos profissionais qualificando-os para qualificar a assistência que prestam aos usuários.

\section{Referências}

Ayres, J. R. C. M. (2004). Cuidado e reconstrução das práticas de saúde. Interface Comunicação, Saúde, Educação, 8(14), 73-91.

Batista, K. B. C., \& Gonçalves, O. S. J. (2011). Formação dos profissionais de saúde para o SUS: Significado e cuidado. Saúde e Sociedade, 20(4), 884-899. Disponível em http://www. scielo.br/pdf/sausoc/v20n4/07.pdf

Bertachini, L. A. (2012). A comunicação terapêutica como fator de humanização da Atenção Primária. O Mundo da Saúde, 36(3), 507-520. Disponível em http://www.saocamilo-sp. $\mathrm{br} / \mathrm{pdf} / \mathrm{mundo}$ saude/95/14.pdf

Brasil. (2004). Ministério da Saúde, Secretaria de Atenção à Saúde, Departamento de Ações Programáticas Estratégicas. Política nacional de atenção integral à saúde da mulher: Princípios e diretrizes. Brasília: Ministério da Saúde.

Brasil. (2008). Ministério da Saúde, Secretaria de Ciência, Tecnologia e Insumos Estratégicos, Departamento de Ciência e Tecnologia. Agenda nacional de prioridades de pesquisa em saúde (2a ed., 68 p., Série B: Textos Básicos em Saúde). Brasília: Ministério da Saúde.

Brasil. (2010). Portaria GM/MS n. 4.279, de 30 de Dezembro de 2010. Estabelece diretrizes para a organização da Rede de Atenção à Saúde no âmbito do Sistema Único de Saúde (SUS). Brasília: Ministério da Saúde.

Brasil. (2012). Ministério da Saúde. Secretaria de Atenção à Saúde. Departamento de Atenção Básica. Política Nacional de Atenção Básica. Brasília : Ministério da Saúde.

Brasil. (2013). Ministério da Saúde. Secretaria de Atenção à Saúde. Departamento de Atenção Básica. Acolhimento à demanda espontânea (1a ed., 1a reimpr.). Brasília: Ministério da Saúde.

Campos, G. W. S. (1997). Considerações sobre a arte e a ciência da mudança: revolução das coisas e reforma das pessoas. O caso da saúde. In L. C. O. Cecílio (Org.), Inventando a mudança na saúde (2a ed., pp. 29-87). São Paulo: Hucitec.

Campos, G. W. S. (2003). Saúde paidéia. São Paulo: Hucitec.

Coelho, E. A. C., Silva, C. T. O., Oliveira, J. F., Almeida, M. S. A. (2009). Integralidade do cuidado à saúde da mulher: Limites da prática profissional. Escola Anna Nery Revista de Enfermagem, 13(1), 154-160.

Fontenele-Mourão, T. M. (2006). Mulheres no topo de carreira: Flexibilidade e persistência. Brasília: Secretaria Especial de Políticas para Mulheres.

Franco, T. B., \& Magalhães Júnior, H. M. (2004). Integralidade na assistência à saúde: A organização das linhas do cuidado. In E. E. Merhy (Org.), O trabalho em saúde: Olhando e experienciando o SUS no cotidiano (2a ed.). São Paulo: Hucitec. 
Franco, T. B., \& Merhy, E. E. (2005). A produção imaginária da demanda e o processo de trabalho em saúde. In R. Pinheiro, \& R. A. Mattos (Orgs.), Construção social da demanda: Direito à saúde, trabalho em equipe, participação e espaços públicos (pp. 181-193). Rio de Janeiro: IMS-UERJ.

Gaskell, G. (2008). Entrevistas individuais e grupais. In M. W. Bauer, \& G. Gaskell, Pesquisa qualitativa com texto, imagem e som: Um manual prático (7a ed., pp. 64-89). Petrópolis, RJ: Vozes.

Gill, R. (2008). Análise de discurso. In M. W. Bauer, \& G. Gaskell, Pesquisa qualitativa com texto, imagem e som: Um manual prático (7a ed., pp. 244-270). Petrópolis, RJ: Vozes.

Gonze, G. G. (2009). A integralidade na formação dos profissionais de saúde: Tecendo saberes e práticas (Dissertação de Mestrado em Saúde Coletiva, Programa de Pós-Graduação em Saúde Coletiva, Universidade Federal de Juiz de Fora, Juiz de Fora, MG).

Lima, D. W. C. (2014). Referenciais teóricos que norteiam a prática de enfermagem em saúde mental. Escola Anna Nery Revista de Enfermagem, 18(2), 336-342.

Manzini, E. J. (2003). Considerações sobre a elaboração de roteiro para entrevista semiestruturada. In M. C. MARQUEZINE, M. A. ALMEIDA, \& S. OMOTE (Orgs.), Colóquios sobre pesquisa em educação especial (pp. 11-25). Londrina: Eduel.

Mattos, R. A. (2006). Os sentidos da integralidade: Algumas reflexões acerca de valores que merecem ser defendidos. In R. A. MATTOS (Org.). Os sentidos da integralidade na atenção e no cuidado à saúde (pp. 48-54). Rio de Janeiro: UERJ/IMS.

Matumoto, S., Fortuna, C. M., Mishima, S. M., Pereira, M. J. B., Domingos, N. A. M. (2005). Supervisão de equipes no Programa de Saúde da Família: Reflexões acerca do desafio da produção de cuidados. Interface - Comunicação, Saúde, Educação, 8(16), 9-24.

Medeiros, F. P., \& Guareschi N. M. F. (2009). Políticas públicas de saúde da mulher: A integralidade em questão. Estudos Feministas, 17(1), 31-48. Disponível em http://www. scielo.br/pdf/ref/v17n1/a03v17n1.pdf

Merhy, E. E. (1997). Em busca do tempo perdido: A micropolítica do trabalho vivo em saúde. In E. E. Merhy, \& R. Onocko (Orgs.), Agir em saúde: Um desafio para o públic (p. 71-112). São Paulo: Hucitec.

Merhy, E. E. (2002a). Saúde: A cartografia do trabalho vivo. São Paulo: Hucitec.

Merhy, E. E. (2002b). Introdução ao debate sobre os componentes da caixa de ferramentas dos gestores em saúde. Caderno de Textos - Versus Brasil, 48-62. Disponível em http:// bvsms.saude.gov.br/bvs/publicacoes/versus_brasil_vivencias_estagios.pdf

Mesquita, A. C., \& Carvalho, E. C. (2014). A escuta terapêutica como estratégia de intervenção em saúde: Uma revisão integrativa. Revista da Escola de Enfermagem da USP, 48(6), 1127-1136.

Oliveira, T. M. V. (2001). Escalas de mensuração de atitudes: Thurstone, Osgood, Stapel, Likert, Guttman, Alpert. Revista Administração Online, 2(2). Disponível em http://www. fecap.br/adm_online/art22/tania.htm

Paim, J. S. (1993). Marco de referência para um programa de educação continuada em Saúde Coletiva. Revista Brasileira de Educação Médica, 17(3), 1-44.

Pedroso, R. T., \& Vieira, M. E. M. (2009). Humanização das práticas de saúde: Transversalizar em defesa da vida. Interface - Comunicação, Saúde, Educação, 13(supl. 1), 695-700. Disponível em http://www.scielo.br/pdf/icse/v13s1/a20v13s1.pdf 
Pierantoni, C. R. (2001). As reformas do Estado, da saúde e recursos humanos: Limites e possibilidades. Ciência \& Saúde Coletiva, 6(2), 341-360.

Pinheiro, R. (2009). Integralidade. In Dicionário da Educação Profissional em Saúde. Disponível em http://www.epsjv.fiocruz.br/sites/default/files/143.pdf

Rinaldi, D. (2000). O acolhimento, a escuta e o cuidado: Algumas notas sobre o tratamento da loucura. Em Pauta: Revista da Faculdade de Serviço Social da UERJ, 16, 7-18.

Scott, J. W. (1995). Gênero: Uma categoria útil de análise histórica. Educação \& Realidade, 20(2), 71-99.

Souza, R. C., Pereira, M. A., \& Kantorski, L. P. (2003). Escuta terapêutica: Instrumento essencial do cuidado em enfermagem. Revista Enfermagem UERJ, 11, 92-97. Disponível em http:// www.facenf.uerj.br/v11n1/v11n1a15.pdf

Souto, K. M. B. (2008). A política de atenção integral à saúde da mulher: Uma análise de integralidade e gênero. SER Social, 10(22), 161-182. Disponível em http://periodicos.unb. $\mathrm{br} /$ index.php/SER_Social/article/view/17

Teixeira, C. (2011). Os princípios do Sistema Único de Saúde. Disponível em https://www. almg.gov.br/export/sites/default/acompanhe/eventos/hotsites/2016/encontro_ internacional_saude/documentos/textos_referencia/07_principios_sistema_unico_ saude.pdf

Vieira, A. N., Silveira, L. C., \& Franco, T. B. (2011). A formação clínica e a produção do cuidado em saúde e na enfermagem. Trabalho, Educação e Saúde, 9(1), 9-24.

Recebido em: 06/04/2017

Última revisão: 17/09/2017

Aceite final: 20/09/2017

\section{Sobre os autores:}

Suzy Anne Lopes de Souza - Psicóloga, Residente Multiprofissional em Saúde da Mulher (HESFA) UFRJ).E-mail: suzylopees@gmail.com

Lia Márcia Cruz da Silveira - Mestre em Tecnologia Educacional em Saúde (UFRJ). E-mail: liadasilveira@gmail.com 